\title{
Effect of applying blended clinical teaching strategies on nursing student's achievement of abdominal examination in pregnancy
}

\author{
Tyseer Marzouk, Nadia Abd Ella \\ Woman's Health and Midwifery Nursing, Faculty of Nursing, Mansoura University, Egypt
}

Received: June 1, 2020

DOI: $10.5430 /$ cns.v8n3p11

\author{
Accepted: July 3, 2020 \\ Online Published: July 13, 2020 \\ URL: https://doi.org/10.5430/cns.v8n3p11
}

\begin{abstract}
Objective: This study aims to evaluate the effect of applying blended clinical teaching strategies on nursing student's achievement of abdominal examination in pregnancy.

Methods: A quasi-experimental research design was implemented on a purposive sample of 105 students registered in the maternity nursing course, Mansoura University, Egpyt. The participants were assigned to the comparison group; who were subjected to the conventional clinical demonstration, the video demonstration group who watched a video clip about the procedure of abdominal examination in pregnancy, or to the blended teaching group, who received both teaching methods. Four tools were used in data collection. Assessment sheet for demographics, student's knowledge and performance were evaluated by Multiple Choice Questions test and performance checklist respectively, while a self-rating scale was used for confidence in clinical performance and satisfaction with the teaching method.

Results: Immediately post-intervention, the blended teaching group had the highest knowledge score compared to the clinical demonstration and video demonstration groups ( $33.8 \pm 1.8$ vs. $30.3 \pm 1.9$ and $24.5 \pm 2.8$ respectively, $p<.001)$, and $38.0 \pm$ 3.1 vs. $33.0 \pm 1.2$ and $28.0 \pm 2.4$ at 2 weeks evaluation and had the highest performance scores $(7.8 \pm 0.9$ and $9.1 \pm 0.8, p<$ .001) immediately and at 2 weeks post-intervention respectively. Similarly, the blended teaching group had the highest confidence in clinical performance and satisfaction with the teaching strategies scores in comparison to the other two groups post-intervention $(8.9 \pm 0.9$ and $9.4 \pm 0.5$ respectively; $p<.001)$.

Conclusions: The study hypotheses were accepted, where blending the video demonstration with the conventional demonstration was an effective strategy for improving the knowledge and clinical performance scores, as well as increasing the confidence in clinical performance and satisfaction with the teaching strategy.
\end{abstract}

Key Words: Blended teaching, Abdominal examination, Clinical performance, Knowledge

\section{INTRODUCTION}

Abdominal examination in pregnancy is a screening procedure that is performed at every prenatal appointment. It includes abdominal inspection, palpation, and fetal heart rate auscultation. ${ }^{[1]}$ The clinical importance of performing ab- dominal palpation from 24 weeks of gestation to approximate fetal weight and from 36 weeks to confirm the fetal position, presentation, lie, and attitude has a globally acclaimed fact; where it aids in deciding the place and mode of delivery. ${ }^{[2]}$ However, most of the maternity nurses had inadequate confidence in their practice. Since correct practice is the safest

\footnotetext{
*Correspondence: Tyseer Marzouk; Email: tm_fathy@yahoo.com; Address: Woman’s Health and Midwifery Nursing, Faculty of Nursing, Mansoura University, Egypt.
} 
investment toward quality care and where correct practice comes from the right education there is a need to update the teaching strategies. ${ }^{[3]}$

The clinical demonstration is the cornerstone of clinical training strategies. It involves a presentation and explanation to show a clinical procedure. Briefly, clinical demonstration is a visualized explanation of a clinical procedure. ${ }^{[4]}$ However, the virtual laboratories that are consigned to provide the students with a chance for attaining the psychomotor skills are inconvenient; where the students' number is more and the faculty members' number is inadequate. Such environment limits the student's chance to hands-on redemonstration. The current situation motivates nurse educators to find a supplementary tool beside the conventional demonstration to complete what is missed inside the laboratory.

Blended teaching is a teaching program that combines more than one teaching strategy to attain the intended learning outcomes. Nowadays, mobile devices become popular in the hands of most of the undergraduates. The mobile-based video was reported to be a more advantageous learning strategy. Blending the mobile device in the learning process is expected to enhance the student's motivation, which was evident to be positively associated with higher students' satisfaction and achievement. It gives a promise to the transition from educator-centered teaching to learner-centered learning. ${ }^{[5-7]}$

However, earlier literature about the effectiveness of video demonstration in transferring psychomotor skills has revealed heterogeneity and little evidence. Some researchers found its use in learning clinical skills is valuable, some repel its use and described it as being addictive, distracting, unprofessional, and time-wasting, while the others suggested use of the video demonstration as an adjunct to the conventional demonstration for clinical skill acquisition. ${ }^{[8-11]}$ Therefore, the present study conducted to evaluate the effect of applying blended clinical teaching strategies on nursing student's achievement of abdominal examination in pregnancy.

\subsection{Significance of the study}

One of the first priorities in teaching nursing curricula is the accuracy of performing the clinical skills to ensure safe patient care. The nurse educators make their efforts to use effective methods in teaching clinical skills. ${ }^{[12]}$ Student's satisfaction with the conventional clinical demonstration strategy in previous national research work was 11.2 points from a total of 25 points; indicating inadequate satisfaction. ${ }^{[13]}$ Blending mobile-based video demonstration as a learning tool with the conventional clinical demonstration is expected to motivate learners to learn. ${ }^{[14]}$ There is little evidence about using blended clinical teaching strategies in Egypt. Thus, the present study was conducted to evaluate the effect of applying blended clinical teaching strategies on nursing student's achievement of abdominal examination in pregnancy.

\subsection{Operational definitions}

\subsubsection{Academic achievement}

The academic performance or achievement can be defined as the level to which a learner has achieved the intended learning outcomes. This is mostly evaluated by continuous assessment of knowledge and clinical performance. ${ }^{[15]}$ In this study, student's satisfaction with the teaching strategy and confidence in practice were also assessed.

\subsubsection{Blended teaching strategies}

Akbarov and coauthors ${ }^{[16]}$ defined blended teaching as a new teaching strategy that blends traditional teaching in its various forms and distance learning in its various forms using advanced technology; in order to enhance learner's motivation and increase academic achievement. Such a definition stipulated blend virtual and physical environments. In the current study, a mobile-based video demonstration was blended with the conventional clinical demonstration.

\subsection{Aim of the study}

This research study aimed to evaluate the effect of applying blended clinical teaching strategies on nursing student's achievement of abdominal examination in pregnancy.

\subsection{Hypotheses of the study}

To achieve the present study aim, two hypotheses were tested.

Hypothesis I: Nursing students who receive blended teaching strategies on abdominal examination in pregnancy exhibit higher scores of knowledge and clinical performance compared with those who receive training either by clinical demonstration or video demonstration alone.

Hypothesis II: Nursing students who receive blended teaching strategies on abdominal examination in pregnancy rate higher confidence in clinical performance and greater satisfaction with the teaching method compared with those who receive training either by clinical demonstration or video demonstration alone.

\section{SUBJECTS AND METHODS}

\subsection{Research design}

This study fits the quasi-experimental research design. This design was chosen to evaluate the effect of the independent variables (i.e., conventional clinical demonstration, video clip watching, or both) on the dependent variables (i.e., students' knowledge, clinical performance, confidence in clinical practice, and satisfaction with the teaching method). 
Three parallel groups were studied; comparison group and two intervention groups.

\subsection{Study settings}

This study was carried out at the Maternity Nursing Laboratory, in the Faculty of Nursing - Mansoura University, Egypt. This lab is a simulated Obstetrics and Gynecology department. It is subdivided into three sections; Antenatal Clinic, Labour and Delivery room, and postpartum room. It includes two high fidelity full-body simulated parturient women; with working programmable fetal monitor and two intermediate fidelity full-body simulated pregnant women (NoelleTM Gaumard simulator).

\subsection{Sampling}

A purposive sample was recruited from female nursing students registered in the Maternity Nursing course during the second semester of the academic year 2016-2017. This course was open for registration of the third-year students of the Nursing Baccalaureate Program during both academic semesters. The student was eligible to enroll in this study if accomplished the following criteria:

(1) Registered in the Maternity Nursing course in the second semester of the academic year 2016-2017 for the first time; was not a repeater to the same course.

(2) Has a smartphone for enabling download the video clip.

(3) Did not receive a lecture or practical training on the assigned skill (i.e., abdominal examination in pregnancy).

(4) Agreed to share in the research work.

\subsubsection{Sample size calculation}

This study aimed to evaluate the effect of applying blended clinical teaching strategies on nursing student's achievement of abdominal examination in pregnancy. Based on data from a previously published study by Devi et al.. ${ }^{[17]}$ considering the level of significance $5 \%$ and a study power of $80 \%$, the sample size was calculated by substitution in Equation 1:

$$
n=\frac{\left(Z_{\frac{\alpha}{2}}+Z_{\beta}\right)^{2} \times 2(S D)^{2}}{(\text { mean difference between the two groups })^{2}}
$$

The $S D=$ standard deviation, $Z_{\frac{\alpha}{2}}$ : depends on the level of significance, for $5 \%$ this is $1.96, Z_{\beta}$ : depends on power, for $80 \%$ this is 0.84 . Therefore, $n=\left[(1.96+0.84)^{2} \times 2\right.$ $\left.\times(10.47)^{2}\right] /(7.0)^{2}=35.1$. Accordingly, the sample size required per group was 35 students with a total sample size of 105 students.

\subsubsection{Group's allocation}

All students registered in the maternity nursing course during the study period were invited to participate in the current research work. Out of a total number of 421 registered students, 175 students were male students or were unwilling to participate in this research, 12 students stated that they had previous experience of watching a video clip about the assigned skill, and 50 did not have smartphones thus excluded leaving 184 eligible students. From the eligible students, the required sample was taken and distributed equally into three groups; comparison group, video demonstration group, or a group of blended teaching strategies (i.e., 35 students per each). From the comparison group, 3 students did not attend the pretest, 2 were absent at the second posttest in the video demonstration group, while from the blended teaching strategies group nobody withdrawn. The dropout number was replaced and the statistical analysis was done on 105 students. The flowchart of the participants is illustrated below.

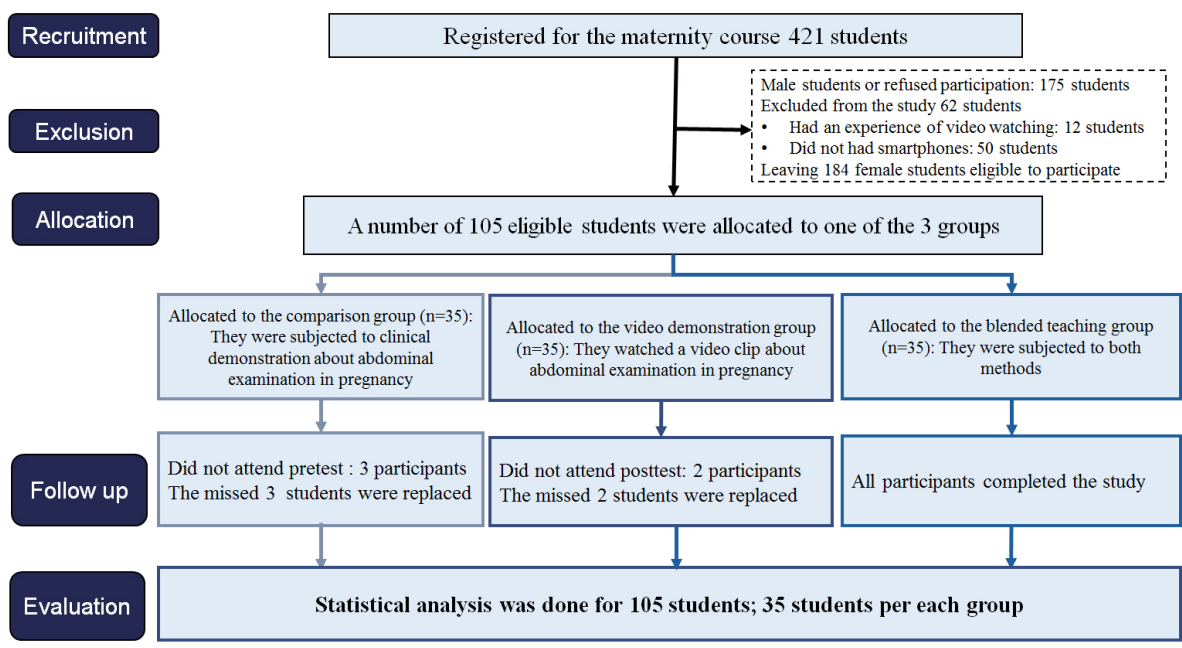

Figure 1. Flowchart of the study participation 


\subsection{Measures of data collection}

Four measures were used in data collection. Assessment sheet, Multiple Choice Questions test, a checklist of performance, and self-rated scale for confidence in clinical performance and satisfaction with the teaching method.

\subsubsection{Assessment sheet}

This was developed by the researcher to collect the general characteristics of the participant students. This sheet included five variables (i.e., name, age, residence, level of interest in the maternity nursing course, and level of class participation). The last two variables were evaluated on a 0 -10 point scale; where 0 indicates the lowest and 10 indicates the highest level. The level of interest with the course was self-evaluated, while the level of class participation was evaluated by the researcher.

\subsubsection{Multiple Choice Questions test (MCQs-test)}

The student's knowledge about the abdominal examination in pregnancy was evaluated by using MCQs-test of 10 multiplechoice questions developed by the researcher. The developed test inquired about the important issues related to the abdominal examination skill; such as the aim of performing the 2 nd maneuver, the correct order of the four maneuvers, the examiner's position in performing the 3rd maneuver, pregnant mother's position during the examination, and ideal gestation weeks at performing abdominal palpation, etc. The correct answer was given a score of one, while the incorrect answer scored zero. Total knowledge score ranged from 0 to 10 points; with a higher score refers to the higher knowledge.

Table 1. Checklist of abdominal examination in pregnancy

\begin{tabular}{l} 
No. Checklist items \\
\hline I. Preparation phase \\
1. Welcome the simulated pregnant mother and inform her about the procedure and its aim. \\
2. Prepare the required equipment (e.g., gloves, measuring tape, Pinard) and prepare the simulated woman for the procedure; by \\
instructing her to evacuate the urinary bladder and lie on the examination table in semi-Fowler's position. As well as, maintain \\
her privacy. \\
II. Abdominal inspection \\
3. Ask the simulated pregnant mother to uncover her abdomen. \\
4. Start the examination by inspecting the abdomen for its size, shape, scars, or skin changes like striae gravidarum or linea nigra. \\
III. Abdominal palpation (Leopold's Maneuvers) \\
Fundal grip - Identify the fundal height
\end{tabular}

5. Wash hands and wear disposable gloves.

6. Stand at the right side of the simulated pregnant mother facing her head.

7. Uncover her abdomen. Palpate the fundus using both hands to identify which fetal part occupying the fundus (e.g., fetal head felt hard and mobile, while fetal buttocks felt soft and irregular).

8. Using the measuring tape, measure the distance from the symphysis pubis to the uterine fundus.

Lateral grip - Identify the fetal position

9. Using both hands try to identify where the fetal back is.

10. Place hands on either side of the simulated pregnant mother's abdomen.

11. Hold one hand on one side of the simulated pregnant mother's abdomen and feel with the other hand both the fetal back or fetal legs and arms. Repeat this step on the opposite side.

12. Identify the fetal position by identifying the fetal occiput is anterior or posterior, and right or left.

First pelvic grip-Identify the fetal presentation

13. By using the thumb and fingers, grasp the lower uterine segment just above the symphysis pubis to determine the presenting part.

14. Palpate a hard round part means cephalic presentation, while soft irregular part means breach presentation.

Second pelvic grip - Identify the fetal attitude

15. Face the simulated pregnant mother's feet and slide hands down the sides of the uterus until meet resistance. It may be the baby's forehead or the occiput. If the forehead is opposite the baby's back, the head is flexed, while if the occiput is the cephalic prominence, the head is extended.

\section{Auscultate to the fetal heart rate}

16. After determining the fetal position, place the pinard on simulated mother's abdomen at the side of fetal back.

17. Place ear in close to the pinard, remove hands and support the pinard by ear.

18. Listen to the fetal heart rate, count it for a full minute. Simultaneously, feel the simulated pregnant mother's pulse at wrist and count it to ensure that the counted rate is the fetal not maternal.

\section{Termination of the procedure}

19. Drape the exposed abdomen and remove the gloves.

20. Document the findings. 


\subsubsection{Checklist of performance}

The clinical performance was evaluated according to a structured checklist. It was developed by the researcher based on the standard guidelines from maternity nursing textbooks and literature. ${ }^{[18,19]}$ The developed checklist consisted of 20 items divided into five sections; preparation for the procedure ( 2 items), abdominal inspection ( 2 items), abdominal palpation or Leopold's maneuvers (i.e., fundal grip, lateral grip, first and second pelvic grips) evaluated by eleven items, auscultation of the fetal heart sound and termination phase were evaluated by three and two items respectively. Each item was scored on a three point rating scale with the scoring criteria of totally correct performance given score of 2 , partially correct performance scored 1 , and totally incorrect or omitted scored 0 . The total clinical performance score ranged between 0 and 40 points. The structured checklist is presented in Table 1.

\subsubsection{Self-rating scale}

The self-rating scale was adopted from a previous study to assess the student's confidence in performing the abdominal examination in pregnancy and the student's satisfaction with the teaching/learning method. ${ }^{[20]}$ It consists of eleven points scale. The rate of student's confidence in performing the procedure was assessed by asking the student to point out; on the 0-10 self-rating scale, the extent to which is feeling confident in performing the procedure. Likewise, the student's level of satisfaction with the teaching method was assessed by asking the student to rate the level of satisfaction with the teaching method on the same scale. The higher reported score refers to a higher level of confidence in clinical performance or higher satisfaction with the learning method. The validity of the self-rating scale was confirmed in a previous study and its reliability was also established. ${ }^{[20]}$ For the current study population, the reliability was proven through Cronbach's $\alpha$ $(0.85)$, indicating that the tool was reliable.

\subsubsection{Validity and reliability of the study measures}

The performance checklist and the MCQs-test were given to three professors in maternity nursing specialty to confirm content validity. The comments were collected and modifications were done in the performance checklist (i.e., two items were merged in one and the steps were categorized under subheadings). No comments were given for the MCQs-test.

To reduce the possible discrepancy between the two evaluators, the reliability of the performance checklist was verified by the test-retest method. In this method, the evaluators of the clinical achievement evaluated ten students not shared in the study. After two weeks the same sample was reevaluated by the same evaluators. Thereafter, the correlation coefficient was calculated and the interrater reliability was assessed be- tween results of the two evaluators; giving a Cronbach's coefficient of 0.91 indicating adequate reliability. Parallel, reliability of the MCQs-test was similarly verified by the test-retest method; giving a correlation coefficient value of 0.89 between the two results; meaning reliable tool.

\subsection{Ethical considerations}

Before initiating the current research work ethical approval was taken from the research ethics committee of the Faculty of Nursing, Mansoura University. All participants gave their informed consent after clarifying the aim and approach of this study. Share in the study was voluntary and each participant had the right to withdraw at any time without penalty or mark deduction. Students' scores were used only for research aim and did not include in students' evaluation scores. At the end of the study, subjects of the comparison group allowed to download the video, and those of the video group received clinical performance training to take advantage effect of both.

\subsection{Research process \\ 2.6.1 Preparation phase}

In this phase, the video-clip was produced and the students were subdivided into subgroups. The video clip of demonstrating the abdominal examination in pregnancy was produced in the Maternity Nursing Laboratory by one of the researchers. The intermediate fidelity full-body simulated pregnant woman mannequin (NoelleTM Gaumard simulator) was used in video production. A digital camera used in recording the clinical demonstration scenes with clear concise voice narration for debriefing. The produced video was 10 minutes and 45 seconds in its duration. The video included a meticulous description of the preparation, steps of performing abdominal inspection and palpation, auscultation of the fetal heart rate, and termination of the procedure. The final produced video shown to three experts of maternity nursing to assess the validity of the principles, precision of the depicted steps, and quality of the recording scenes and voice narration; before its release to the participant students. Thereafter, each of the comparison and blended groups was subdivided into three subgroups (11-12 students per each) to avoid students crowding inside the laboratory. Making six groups received lab training on six days, while the video group did not divided to subgroups because each member learned individually.

\subsubsection{Implementation phase The comparison group}

The comparison group received their clinical training by the clinical demonstration which is the conventional method adopted by the maternity staff for teaching clinical proce- 
dures. The conventional demonstration session started at $8.00 \mathrm{am}$ and ended at $2.00 \mathrm{pm}$ and ran according to the following sequence: the first 30 minutes for students' absenteeism, from 8.30 until 9.30 the pretest was done for a small group of 11-12 students. The instructor started by a PowerPoint presentation through which all items of performing the abdominal examination in pregnancy were clarified; from getting ready until termination of the procedure within 90 minutes. During this period students were instructed to observe the steps performed and inquire about any unclear points. Thereafter, the clinical demonstration was performed by the instructor on a simulated pregnant woman in about 30 minutes. After a break of 30 minutes, the posttest was done by instructing each student to redemonstrate the steps and corrections provided by the researcher at the end of the session. This step accomplished in about 120 minutes.

\section{The video demonstration group}

This group learned individually by watching a video clip about the assigned procedure. For the first time, the students watched the video at the maternity nursing laboratory under supervision of a researcher. Each student allowed to download a copy from the video on own mobile. Students in this group instructed to watch the video once daily for two weeks. Students saw the video at their homes, during transportation time, or any suitable place and at anytime.

\section{The blended teaching strategies group}

This group received their clinical training by conventional clinical demonstration, then the video clip was presented immediately after clinical demonstration. Thereafter, each student in this group was instructed to download the video on her own mobile to watch it once daily for the following two consecutive weeks. Student's compliance with video watching was attained when the students of the video demon- stration and blended teaching groups watched the video for at least ten times.

\subsubsection{Evaluation of the study outcomes}

The baseline evaluation was done immediately before the intervention for students' level of knowledge and clinical skill performance. The clinical skill performance was evaluated blindly by the two trained volunteer demonstrators. Two post-intervention evaluations were done; the first was immediately after the intervention for knowledge and clinical performance achievement; while the second was after two weeks from the baseline evaluation for the previously mentioned outcomes besides student's satisfaction with the clinical teaching method and confidence in clinical performance.

\subsection{Statistical analysis}

All statistical analyses were performed using SPSS for windows version 20.0 (SPSS, Chicago, IL). All variables contained continuous data of normal distribution were expressed in mean \pm standard deviation $(S D)$. The comparisons were determined using Student's $t$-test for two variables or oneway ANOVA test for comparison among more than two variables. Statistical significance was set at $p<.05$.

\section{RESULTS}

\subsection{General characteristics of the participants and ho- mogeneity}

Table 2 compares the general characteristics of the three studied groups. The mean age, students' level of interest with the subject, and the level of class participation showed no significant difference among the three groups. Similarly, the distribution of residence did not differ significantly among the three groups.

Table 2. General characteristics of the participant students $(\mathrm{N}=105)$

\begin{tabular}{|c|c|c|c|c|c|c|c|}
\hline \multirow[b]{2}{*}{ Characteristics } & \multicolumn{3}{|c|}{ Groups } & \multicolumn{4}{|c|}{ Comparisons } \\
\hline & $\begin{array}{l}\text { Clinical demonstration } \\
\qquad(\mathbf{n}=35)\end{array}$ & $\begin{array}{l}\text { Video demonstration } \\
(\mathbf{n}=35)\end{array}$ & $\begin{array}{l}\text { Blended teaching } \\
\qquad(\mathrm{n}=35)\end{array}$ & $F[P]$ & $T_{1}\left[P_{1}\right]$ & $T_{2}\left[P_{2}\right]$ & $T_{3}\left[P_{3}\right]$ \\
\hline \multicolumn{8}{|l|}{ Age (years) } \\
\hline Range & $20-22$ & $20-22$ & $20-22$ & 0.992 & 0.463 & 1.373 & 0.924 \\
\hline Mean $\pm S D$ & $21.1 \pm 0.8$ & $21.0 \pm 0.8$ & $20.8 \pm 0.8$ & {$[.375]$} & {$[.645]$} & {$[.174]$} & {$[.359]$} \\
\hline \multicolumn{8}{|l|}{ Residence } \\
\hline Rural & $19,54.3 \%$ & $18,51.4 \%$ & $20,57.1 \%$ & $X^{2}=0.230$ & $X_{1}^{2}=0.057$ & $\mathrm{X}_{2}^{2}=0.058$ & $\mathrm{X}_{3}^{2}=0.810$ \\
\hline \multicolumn{8}{|c|}{ Level of interest with the subject } \\
\hline Range & $7-10$ & $8-10$ & $7-9$ & 1.292 & 0.789 & 0.758 & 1.759 \\
\hline Mean $\pm S D$ & $8.4 \pm 1.2$ & $8.6 \pm 0.9$ & $8.2 \pm 1.0$ & {$[.279]$} & {$[.433]$} & [.451] & {$[.083]$} \\
\hline \multicolumn{8}{|c|}{ Level of class participation } \\
\hline Range & $8-10$ & $7-9$ & $7-10$ & 1.077 & 1.592 & 0.721 & 0.695 \\
\hline Mean $\pm S D$ & $8.3 \pm 1.0$ & $7.9 \pm 1.1$ & $8.1 \pm 1.3$ & {$[.344]$} & [.116] & [.473] & [.490] \\
\hline
\end{tabular}

Note. $F$, comparison among the 3 groups, $T_{1}$ or $X_{1}$, comparison between demonstration group and video demonstration group, $T_{2}$ or $X_{2}$ comparison between demonstration group and blended group, $T_{3}$ or $X_{3}$ comparison between video demonstration group and blended group 


\subsection{Effect of implementing the teaching strategies on the} clinical performance scores

The clinical skill scores on abdominal examination in pregnancy were compared among the studied groups preintervention and immediately and 2 weeks post-intervention. At baseline, no significant differences were found among the studied groups. Immediately post-intervention, the mean differences of clinical skill scores among the groups were statistically significant, with the blended group had the highest score and the clinical demonstration group comes next while it is lowest in the video demonstration group $(33.8 \pm 1.8$, $30.3 \pm 1.9$ and $24.5 \pm 2.8$ respectively, $p<.001)$ as shown in Table 3. Similarly, at 2-weeks post-intervention, the mean differences of clinical skill scores among the groups were statistically significant $(p<.001)$. The blended group had the highest score $(38.0 \pm 3.1)$, the clinical demonstration group had a score of $33.0 \pm 1.2$ while the video demonstration group had the lowest score of $28.0 \pm 2.4$.

Table 3. Comparison of the clinical skill scores on abdominal examination in pregnancy of the three groups before and after the interventions $(\mathrm{N}=105)$

\begin{tabular}{|c|c|c|c|c|c|c|c|}
\hline \multirow[b]{2}{*}{$\begin{array}{c}\text { Clinical skill } \\
\text { scores } \\
\text { (Total }=40)\end{array}$} & \multicolumn{3}{|c|}{ Groups } & \multicolumn{4}{|c|}{ Comparisons } \\
\hline & $\begin{array}{c}\text { Clinical } \\
\text { demonstration } \\
(\mathbf{n}=\mathbf{3 5})\end{array}$ & $\begin{array}{c}\text { Video } \\
\text { demonstration } \\
(\mathbf{n}=\mathbf{3 5})\end{array}$ & $\begin{array}{l}\text { Blended } \\
\text { teaching } \\
(n=35)\end{array}$ & $\boldsymbol{F}[\boldsymbol{P}]$ & $\boldsymbol{T}_{1}\left[\boldsymbol{P}_{1}\right]$ & $\boldsymbol{T}_{2}\left[\boldsymbol{P}_{2}\right]$ & $T_{3}\left[P_{3}\right]$ \\
\hline \multicolumn{8}{|c|}{ Pre-intervention } \\
\hline Range & $6-8$ & $7-9$ & $6-9$ & 0.955 & 1.515 & 0.642 & 0.688 \\
\hline Mean $\pm S D$ & $7.1 \pm 1.2$ & $7.5 \pm 1.0$ & $7.3 \pm 1.4$ & {$[.338]$} & {$[.134]$} & {$[.523]$} & {$[.494]$} \\
\hline \multicolumn{8}{|c|}{ Immediately post-intervention } \\
\hline Range & $27-33$ & $21-29$ & $31-37$ & 157.323 & 10.202 & 7.776 & 16.527 \\
\hline Mean $\pm S D$ & $30.3 \pm 1.9$ & $24.5 \pm 2.8$ & $33.8 \pm 1.8$ & {$[<.001]$} & {$[<.001]$} & {$[<.001]$} & {$[<.001]$} \\
\hline \multicolumn{8}{|c|}{ Two weeks post-intervention } \\
\hline Range & $32-36$ & $24-32$ & $34-40$ & 156.157 & 11.024 & 8.899 & 15.090 \\
\hline Mean $\pm S D$ & $33.0 \pm 1.2$ & $28.0 \pm 2.4$ & $38.0 \pm 3.1$ & {$[<.001]$} & {$[<.001]$} & {$[<.001]$} & {$[<.001]$} \\
\hline
\end{tabular}

Note. $F$, comparison among the 3 groups, $T_{1}$ or $X_{1}$, comparison between demonstration group and video demonstration group, $T_{2}$ or $X_{2}$ comparison between demonstration group and blended group, $T_{3}$ or $X_{3}$ comparison between video demonstration group and blended group

Table 4. Comparison of the knowledge scores on abdominal examination in pregnancy of the three groups before and after the clinical training $(\mathrm{N}=105)$

\begin{tabular}{|c|c|c|c|c|c|c|c|}
\hline \multirow[b]{2}{*}{$\begin{array}{l}\text { Knowledge } \\
\text { scores } \\
(\text { Total }=10)\end{array}$} & \multicolumn{3}{|c|}{ Groups } & \multicolumn{4}{|c|}{ Comparisons } \\
\hline & $\begin{array}{c}\text { Clinical } \\
\text { demonstration } \\
(\mathbf{n}=\mathbf{3 5})\end{array}$ & $\begin{array}{c}\text { Video } \\
\text { demonstration } \\
(\mathbf{n}=\mathbf{3 5})\end{array}$ & $\begin{array}{l}\text { Blended } \\
\text { teaching } \\
(n=35)\end{array}$ & $F[P]$ & $T_{1}\left[P_{1}\right]$ & $T_{2}\left[P_{2}\right]$ & $T_{3}\left[P_{3}\right]$ \\
\hline \multicolumn{8}{|c|}{ Pre-intervention } \\
\hline Range & $1-3$ & $1-3$ & $1-3$ & 1.172 & 0.983 & 1.474 & 0.523 \\
\hline Mean $\pm S D$ & $2.0 \pm 0.9$ & $1.8 \pm 0.8$ & $1.7 \pm 0.8$ & {$[.314]$} & {$[.329]$} & {$[.145]$} & {$[.603]$} \\
\hline \multicolumn{8}{|c|}{ Immediately post-intervention } \\
\hline Range & $5-8$ & $3-5$ & $7-9$ & 124.330 & 8.283 & 6.705 & 18.188 \\
\hline Mean $\pm S D$ & $6.1 \pm 1.2$ & $4.0 \pm 0.9$ & $7.8 \pm 0.9$ & {$[<.001]$} & {$[<.001]$} & {$[<.001]$} & {$[<.001]$} \\
\hline \multicolumn{8}{|c|}{ Two weeks post-intervention } \\
\hline Range & $5-9$ & $4-6$ & $8-10$ & 155.658 & 5.411 & 11.309 & 19.161 \\
\hline Mean $\pm S D$ & $6.5 \pm 1.1$ & $5.2 \pm 0.9$ & $9.1 \pm 0.8$ & {$[<.001]$} & {$[<.001]$} & {$[<.001]$} & {$[<.001]$} \\
\hline
\end{tabular}

Note. $F$, comparison among the 3 groups, $T_{1}$ or $X_{1}$, comparison between demonstration group and video demonstration group, $T_{2}$ or $X_{2}$ comparison between demonstration group and blended group, $T_{3}$ or $X_{3}$ comparison between video demonstration group and blended group

\subsection{Effect of implementing the teaching strategies on the knowledge scores}

As regards the knowledge scores on abdominal examination in pregnancy, it is clear from Table 4 that the differences

Published by Sciedu Press among the studied groups were insignificant at baseline. However, immediately post- intervention, the blended group had the best score $(7.8 \pm 0.9)$, the clinical demonstration group comes next $(6.1 \pm 1.2)$ while the video demonstration 
group had the lowest score $(4.0 \pm 0.9)$, these differences were significant $(p<.001)$. Likewise, at 2 -weeks post-intervention, the blended group had the best knowledge score $(9.1 \pm 0.8)$, followed by the clinical demonstration group $(6.5 \pm 1.1)$ with the video demonstration group had the lowest score (5.2 $\pm 0.9)$, these differences were significant $(p<.001)$.

3.4 Effect of implementing the teaching strategies on the student's confidence in practice and satisfaction with the teaching method

Figure 2 shows that the students in the blended group had the highest confidence of clinical performance score followed by the clinical demonstration group while the students in the video demonstration group had the lowest confidence of clinical performance score $(8.9 \pm 0.9$ vs. $6.8 \pm 0.8$ and $4.1 \pm 0.9$ respectively). Figure 3 illustrates that the score of satisfaction with the teaching method was highest in the blended group with the clinical demonstration group comes next and it is lowest in the video demonstration group (9.4 \pm 0.5 vs. $7.8 \pm 0.8$ and $5.2 \pm 0.8$ respectively; $p<.001)$. The differences among the three studied groups regarding confidence in practice and satisfaction with the teaching strategies were significant $(p<.001)$.

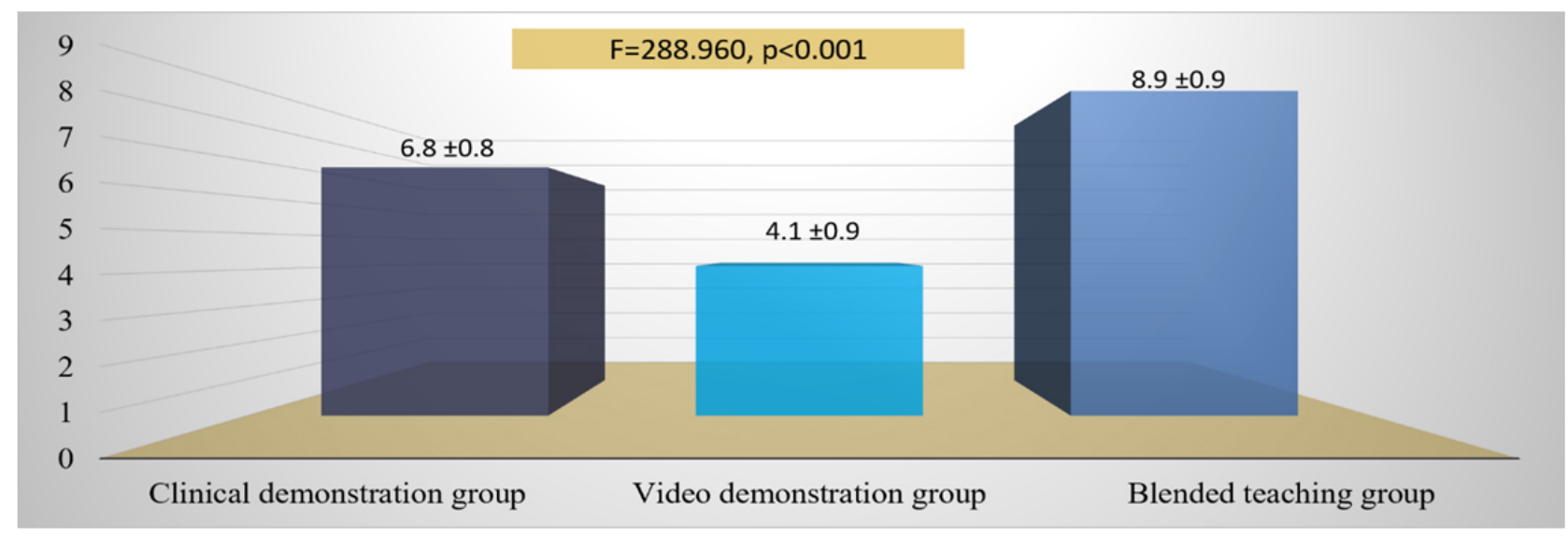

Figure 2. Comparison of the students' confidence of clinical performance at the end of the study among the three groups

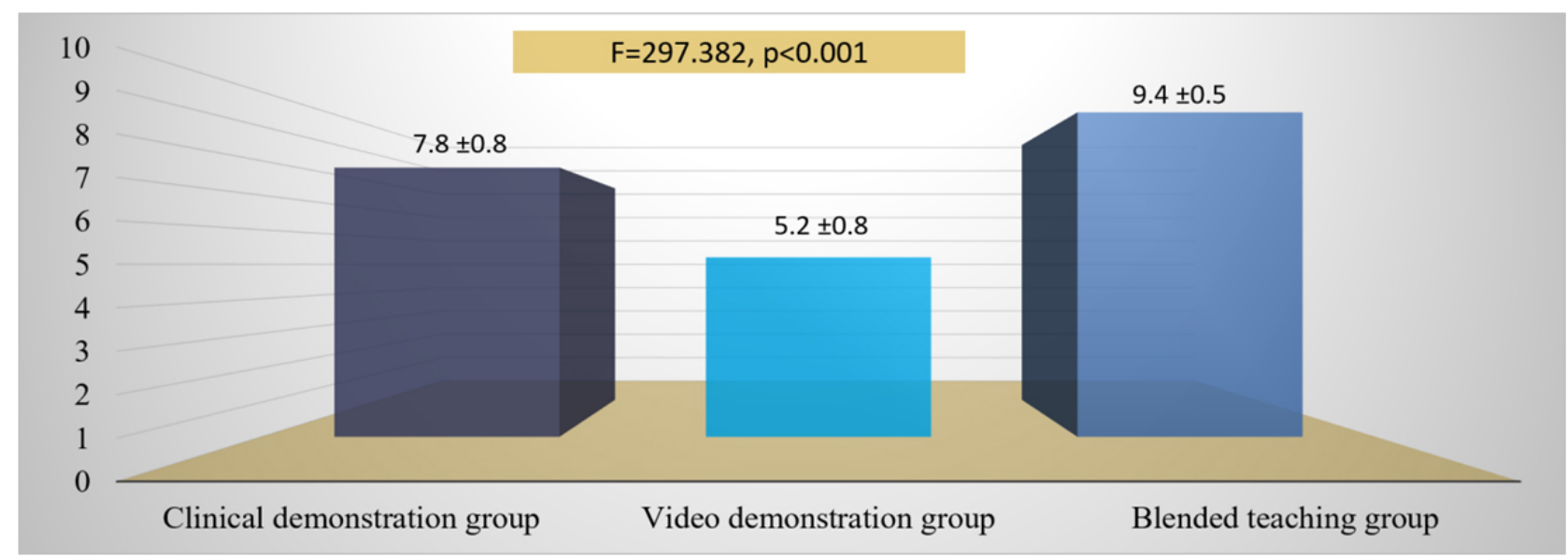

Figure 3. Comparison of the students' satisfaction with the teaching method at the end of the study among the three groups

\section{Discussion}

The current study aims to evaluate the effect of applying blended clinical teaching strategies on nursing student's achievement of abdominal examination in pregnancy. This aim was achieved through the current study results which revealed a significant increase in scores of knowledge and clinical skill performance among subjects of the blended teaching strategies compared to those received either clinical demonstration or video demonstration alone. Furthermore, the clinical demonstration group had higher scores in comparison to the video demonstration group. Thus, supporting the first study hypothesis; "Nursing students who receive 
blended teaching strategies on abdominal examination in pregnancy exhibit higher scores of knowledge and clinical performance compared with those who receive training either by clinical demonstration or video demonstration alone."

The use of video in teaching clinical skills is not a novel strategy. Its benefits documented in earlier studies. However, these studies were criticized by small sample size or lack of studying the effect of video watching merely. The current study is advantageous by an adequate sample size and studying each teaching strategy alone. The current study results reveal a significantly higher increase in clinical skill performance scores among students of the blended teaching strategies compared to their mates in the clinical demonstration or video demonstration groups. Additionally, the clinical demonstration results in higher clinical performance scores in comparison to the video demonstration.

A recent quasi-experimental study, ${ }^{[17]}$ with a pretest-posttest and control group compared effects of video-assisted teaching versus conventional demonstration on clinical performance of abdominal examination among 60 nursing students in India. The study revealed a significant improvement in clinical skill performance scores of abdominal examination in pregnancy among subjects of the clinical demonstration group in comparison to their mates in the video-assisted teaching group; supporting findings of the present study. Furthermore, in a quantitative-qualitative study in Australia explored nursing students' experience of e-learning, Bloomfield and Jones ${ }^{[21]}$ reported that the students did not wish to abandon conventional clinical teaching methods and declare a combination of the blended teaching strategies.

Authors of the present study attributed the higher clinical performance scores among the blended teaching strategies to that the video demonstration complement what is lost in the clinical demonstration. The video can help the students to memorize the palpation steps but never attain the palpation sense that is necessary for fetal parts verification. Meanwhile, conventional demonstration allows the students to feel the fetal parts; thus achieved higher performance scores equated to the video demonstration alone. This finding confirming that the video demonstration cannot be an alternative to the clinical demonstration; rather it can be a supplement to it.

In spite of teaching abdominal palpation through conventional clinical demonstration is valuable in comparison to watching the related video, the present study findings revealed that combining clinical demonstration with video demonstration was more advantageous on improving the student's knowledge. Consistently, Sheikhaboumasoudi et al., 2018 in a posttest experimental study carried out in Iran on 60 nursing students, found a statistically significant higher knowledge score of students who received clinical training through a blend of e-learning with traditional clinical teaching compared to their mates in traditional teaching only. ${ }^{[22]}$ The higher knowledge score in the blended method may be explained by that smearing both methods simultaneously acquired the students with benefits of both methods. As, the students gain knowledge and practical skills at the skill laboratory and mobile learning acquire them with a chance of continuous studying anywhere and anytime. The advantage which motivates student's learning and increasing the gain of knowledge. Partially agreed with the present study finding, Lee and coauthors ${ }^{[20]}$ found higher knowledge scores among nursing students received clinical training via video-assisted teaching as an adjunct to the traditional demonstration; however, the difference was not statistically significant. The present study authors attribute the insignificant difference to that the students were assessed after one week from watching the video compared to two weeks in the present study. Supporting the suggestion of Hansen and colleagues ${ }^{[23]}$ who recommended that to get better learning outcomes it is important to view the video clip for more than 1 week.

Feeling of confidence in clinical performance is not less important than knowledge and clinical performance; thus researchers of the current study were keen to assess it on a 0-10 self-rated scale. It was evident in the current study that students of the blended teaching group rated higher confidence in comparison to their mates in mere clinical demonstration or video demonstration groups. The same finding was observed by Lee and coauthors; ${ }^{[20]}$ where students received blended methods of teaching rated higher confidence by 1.27 points on the same scale in comparison to their mates in traditional teaching. Furthermore, Lee and coauthors noted that the students seemed lower anxious about making faults and more ready for clinical practice transition. Correspondingly, medical students who joined watched the online video with clinical demonstration expressed about their readiness for clinical practice, while their mates who received traditional teaching alone found the learning experience away from clinical experience. Elevation of confidence rating in the blended teaching group can be attributed to that the repeated watching of the video clip enables the students to correct misunderstanding and results in reducing student's level of anxiety about making mistakes and feeling more confident.

The current study participants in the blended teaching group rated higher satisfaction with the teaching method at the end of the study equated to participants in the other two groups. Meanwhile, satisfaction with the conventional clinical demonstration was higher than that of video demonstration only. Supporting the second study hypothesis; "Nursing students who receive blended teaching strategies on abdomi- 
nal examination in pregnancy rate higher confidence in clinical performance and greater satisfaction with the teaching method compared with those who receive training either by clinical demonstration or video demonstration alone."

This result consistent with that of Lee and colleagues ${ }^{[20]}$ and Clay ${ }^{[24]}$ who were reported that most of the students received clinical training by clinical demonstration in conjunction with video demonstration rated higher satisfaction with the learning experience equated to those in conventional teaching only. The large numbers of students in relation to the inadequate number of faculty members in undergraduate skills laboratories may increase students' needs to supplement the restricted access to proficient instruction. This may explain the higher satisfaction rating in the blended teaching group; where the students perceive the free access to video could complement the missed during the clinical demonstration.

\subsection{Strengths and limitations}

The present study is advantageous over previous studies by studying distinct groups for evaluating the effect of a video demonstration, clinical demonstration, or both on the nursing students' performance of the abdominal examination in pregnancy. This advantage enables the current study to produce robust evidence for the effect of a combination of video demonstration with clinical demonstration in comparison to each one merely. Contrariwise, applying different clinical teaching strategies on abdominal examination only was a limitation of the current study.

\subsection{Implications in nursing education}

The use of mobile-based videos are accessible and available with no restrictions of time or place. Its use could supplement inadequate access to faculty members. It allows students to study anywhere and anytime chosen. Despite it cannot acquire a sense of hands-on, it can be helpful if used with clinical skill demonstration; where it enhances student's responsibility of learning.

\section{CONCLUSION AND RECOMMENDATIONS}

The present study findings revealed that the established hypotheses were accepted. The students who were subjected to the blended clinical teaching strategies recorded higher scores of knowledge and clinical performance in the assigned procedure. As well as, rated higher confidence in clinical performance and higher satisfaction with the teaching method equated to their mates who received clinical demonstration or video demonstration alone. Hence, the following can be recommended:

(1) Nursing educators should work on the blend of modern technology with the conventional clinical demonstration.

(2) Future research should be directed towards exploring learners' views and experiences of blended teaching strategies.

\section{CONFLicts OF InTEREST Disclosure}

The authors declare they have no conflicts of interest.

\section{REFERENCES}

[1] Peleg D, Warsof S. Hands off-Disappearance of the abdominal examination during pregnancy. Birth. 2019 Dec; 46(4): 547-549. Epub 2019 Aug 30. PMid: 31471915. https ://doi.org/10.1111/bi rt. 12449

[2] Neelimarani GR. A study to assess the knowledge gain with video based teaching on kangaroo mother care among B.Sc. Nursing III year students at NIMS Hyderabad; 2010 [Accessed on 2017 Jan 22]. Available from: http://nursingresearchstudies.blogspot . com

[3] Mak C, Wong HS. Assessing women in pregnancy and labour: is it better to palpate? A perspective from midwives. Hong Kong. J Gynaecol Obstet Midwifery. 2000; 1: 86-95.

[4] Viswasom A, Jobby A. Effectiveness of Video Demonstration over Conventional Methods in Teaching Osteology in Anatomy. J Clin Diagn Res. 2017 Feb; 11(2): JC09-JC11. Epub 2017 Feb 1. PMid: 28384890. https://doi.org/10.7860/JCDR/2017/24029.94 29

[5] Dziuban C, Graham C, Moskal P, et al. Blended learning: the new normal and emerging technologies. Int. J. Educ. Technol. Higher. Educ. 2018; 15(3): 1-16.
[6] Taylor JC. Distance education technologies: the fourth generation. Aust. J. Educ. Technol. 1995; 11(2): 1-7. Available from: http://www.ascilite.org.au/ajet/ajet11/taylor.html

[7] Gagnon MP, Gagnon J, Desmartis M, et al. The impact of blended teaching on knowledge, satisfaction, and self-directed learning in nursing undergraduates: a randomized, controlled trial. Nurs Educ Perspect. 2013; 34(6): 377-382. PMid: 24475598. https : //doi.org/10.5480/10-459

[8] Jeong H. Effects of Nursing Students' Practices using Smartphone Videos on Fundamental Nursing Skills, Self-efficacy, and Learning Satisfaction in South Korea. Eurasia Journal of Mathematics, Science \& Technology Education. 2017; 13(6): 2351-2365. https://doi.org/10.12973/eurasia.2017.01229a

[9] McIntosh C, Patterson J, Miller S. First year midwifery students' experience with self-recorded and assessed video of selected midwifery practice skills at Otago Polytechnic in New Zealand. Nurse Education in Practice. 2017; 28: 54-59. PMid: 28950150. https: //doi.org/10.1016/j.nepr.2017.09.016

[10] Cho S, Lee E. Distraction by smartphone use during clinical practice and opinions about smartphone restriction policies: A cross-sectional descriptive study of nursing students. Nurse Education Today. 2016; 
40: 128-133. PMid: 27125162. https://doi.org/10.1016/j. nedt. 2016.02 .021

[11] McNally G, Frey G, Crossan M. Nurse manager and student nurse perceptions of the use of personal smartphones or tablets and the adjunct applications, as an educational tool in clinical settings. Nurse Education in Practice. 2017; 23: 1-7. PMid: 28137514. https://doi.org/10.1016/j.nepr.2016.12.004

[12] Moule P. Simulation in nurse education: Past, present and future. Nurse Educ Today. 2011; 31: 645 6. PMid: 21561689. https: //doi.org/10.1016/j.nedt.2011.04.005

[13] Marzouk TM. Effectiveness of simulated delivery room classes on practical achievement and satisfaction of maternity nursing students. Journal of Nursing Education and Practice. 2015; 5(8): 51-59. https://doi.org/10.5430/jnep.v5n8p51

[14] Button D, Harrington A, Belan I. E learning \& information communication technology (ICT) in nursing education: A review of the literature. Nurse Educ Today. 2014; 34: 1311-23. PMid: 23786869. https://doi.org/10.1016/j.nedt.2013.05.002

[15] Annie W, Stoker HW, Murray-Ward M. Achievement and Ability Tests - Definition of the Domain. Educational Measurement. University Press of America; 1996. 2-5 p. ISBN 978-0-7618-0385-0.

[16] Akbarov A, Gonen K, Aydogan H. Students' attitudes toward blended learning in EFL context. Acta Didact. Napoc. 2018; 11(1): 61-68. https://doi.org/10.24193/adn.11.1.5

[17] Devi B, Khandelwal B, Das M. Comparison of the effectiveness of video-assisted teaching program and traditional demonstration on nursing students learning skills of performing obstetrical palpation. Indian J Neonatal Med Res. 2019; 24: 118-23. PMid: 30820223. https://doi.org/10.4103/ijnmr.IJNMR_35_18
[18] Cunningham FG, Leveno MD, Bloom S, et al. Normal labor \& delivery. In: Williams Obstetrics. 22nd ed. London: McGraw-Hill; 2008. 409-42 p.

[19] Webb SS, Plana MN, Zamora J, et al. Abdominal palpation to determine fetal position at labor onset: a test accuracy study. Acta Obstet Gynecol Scand. 2011 Nov; 90(11): 1259-66. Epub 2011 Jul 27. PMid: 21699499 . https ://doi.org/10.1111/j.1600-041 2.2011.01226. $\mathrm{x}$

[20] Lee NJ, Chae SM, Kim H, et al. Mobile Based Video Learning Outcomes in Clinical Nursing Skill Education: A Randomized Controlled Trial. Comput Inform Nurs. 2016 Jan; 34(1): 8-16. PMid: 26389858. https://doi.org/10.1097/CIN.00000000000001 83

[21] Bloomfield JG, Jones A. Using e-learning to support clinical skills acquisition: exploring the experiences and perceptions of graduate firstyear pre-registration nursing students - a mixed method study. Nurse Educ Today. 2013 Dec; 33(12): 1605-11. Epub 2013 Mar 7. PMid: 23473860. https://doi.org/10.1016/j.nedt.2013.01.024

[22] Sheikhaboumasoudi R, Bagheri M, Hosseini SA, et al. Improving nursing students' learning outcomes in fundamentals of nursing course through combination of traditional and e-learning methods. Iranian J Nursing Midwifery Res. 2018; 23: 217-21. PMid: 29861761. https ://doi.org/10.4103/ijnmr.IJNMR_79_17

[23] Hansen M, Oosthuizen G, Windsor J, et al. Enhancement of medical interns' levels of clinical skills competence and self-confidence levels via video iPods: pilot randomized controlled trial. J Med Internet Res. 2011; 13(1): e29. PMid: 21447471. https ://doi.org/10.2 196/jmir. 1596

[24] Clay CA. Exploring the use of mobile technologies for the acquisition of clinical skills. Nurse Educ Today. 2011; 31(6): 582-586. PMid: 21112132. https://doi.org/10.1016/j.nedt.2010.10.011 